\title{
Some q-rung orthopair fuzzy Muirhead means with their application to multi- attribute group decision making
}

Article

Accepted Version

Wang, J., Zhang, R., Zhu, X., Zhou, Z., Shang, X. and Li, W. (2019) Some q-rung orthopair fuzzy Muirhead means with their application to multi-attribute group decision making. Journal of Intelligent \& Fuzzy Systems, 36 (2). pp. 1599-1614. ISSN 1875-8967 doi: https://doi.org/10.3233/JIFS-18607 Available at https://centaur.reading.ac.uk/80774/

It is advisable to refer to the publisher's version if you intend to cite from the work. See Guidance on citing.

To link to this article DOI: http://dx.doi.org/10.3233/JIFS-18607

Publisher: IOS Press

All outputs in CentAUR are protected by Intellectual Property Rights law, including copyright law. Copyright and IPR is retained by the creators or other copyright holders. Terms and conditions for use of this material are defined in the End User Agreement.

www.reading.ac.uk/centaur 
Central Archive at the University of Reading

Reading's research outputs online 


\title{
Some $q$-rung orthopair fuzzy Muirhead means with their application to multi- attribute group decision making
}

\author{
Jun Wang ${ }^{\mathrm{a}}$, Runtong Zhang ${ }^{\mathrm{a}, *}$, Xiaomin Zhu ${ }^{\mathrm{b}}$, Zhen Zhou' ${ }^{\mathrm{c}}$ Xiaopu Shang ${ }^{\mathrm{a}}$, and Weizi $\mathrm{Li}^{\mathrm{d}}$ \\ ${ }^{a}$ School of Economics and Management, Beijing Jiaotong University, Beijing, China \\ ${ }^{\mathrm{b}}$ School of Mechanical, Electronic and Control Engineering, Beijing Jiaotong University, Beijing, China \\ 'School of Management, Capital Normal University, Beijing, China \\ ${ }^{d}$ Informatics Research Centre, Henley Business School, University of Reading, Reading, UK
}

\begin{abstract}
Recently proposed $q$-rung orthopair fuzzy set ( $q$-ROFS) is a powerful and effective tool to describe fuzziness, uncertainty and vagueness. The prominent feature of $q$-ROFS is that the sum of membership and non-membership degrees is allowed to be greater than the one with the sum of $q$ th power of the membership degree and $q$ th power of the non-membership degree, which is equal to or less than 1 . This characteristic makes the $q$-ROFS more powerful and useful than intuitionistic fuzzy set (IFS) and Pythagorean fuzzy set (PFS). The aim of this paper is to develop some aggregation operators for fusing $q$ rung orthopair fuzzy information. As the Muirhead mean (MM) is considered as a useful aggregation technology which can capture interrelationships among all aggregated arguments, we extend the MM to $q$-rung orthopair fuzzy environment and propose a family of $q$-rung orthopair fuzzy Muirhead mean operators. Moreover, we investigate some desirable properties and special cases of the proposed operators. Further, we apply the proposed operators to solve multi-attribute group decision making (MAGDM) problems. Finally, a numerical instance as well as some comparative analysis are provided to demonstrate the validity and superiorities of the proposed method.
\end{abstract}

Keywords: $q$-rung orthopair fuzzy set, Muirhead mean, $q$-rung orthopair fuzzy Muirhead mean, multi-attribute group decision making

\section{Introduction}

Due to the increasing complexity in economics and management, we have to face decision making problems in different complicated environments. As fuzziness and uncertainty always exist in decision making, one of the most important problems is to represent attribute values appopriately. Recently, quite a few tools have been developed for describing and expressing fuzziness and vagueness. For instance, Zadeh [1] proposed the fuzzy set (FS). Owing to the ability of FSs in modelling fzziness and uncertainty, decision making based on FSs has received much attention [2-5]. However, the drawback of the FS is that it only has a membership degree but ingores

*Corresponding author. Runtong Zhang, School of Management and Economic, Beijing Jiaotong University, Beijing, China. Tel.: +86 01051683854; E-mail: rtzhang@bjtu.edu.cn. uncertain information in real decision making problems. To overcome the drawback of FS, Atanassov [6] proposed the concept of IFS, characterized by a membership degree and a nonmembership degree. This characteristic makes it more powerful and useful than FS. After the apperance of IFSs, quite a few scholars strated to study them extensively and deeply [7, 8]. For instance, $\mathrm{Xu}$ [9] proposed a family of intuitionistic fuzzy simple weighted averaging operators. $\mathrm{Xu}$ and Yager [10], Xia et al. [11] , and Verma [12] proposed several intuitionistic fuzzy Bonferroni mean operators, which can capture the interrelationship among intuitionistic fuzzy numbers (IFNs) respectively. Simarily, Yu [13] extened the classical Heoronian mean to intuitionsitci fuzzy environment and developed a series of intuitionistic fuzzy Heronian mean operators. Considering that in some 
situations attributes and decision makers are in different priority levels, Verma and Sharma [14] proposed a intuitionistic fuzzy Einstein prioritized weighted average operators. Verma and Sharma [15] presented a novle measure of inaccuracy between IFSs and applied it in intuitionsictic fuzzy MADM. Verma and Sharma [16] proposed an exponential intuitionistic in the setting of IFSs. Wang et al. [17] proposed ordered weighted operators for aggregating intuitionistic linguistic numbers. Xia [18] introduced point operators for intuitionistic multiplicative information, which can redistribute the uncertain information according to different preferences of decision makers. Furthermore, considering that IFSs can effectively cope with fuzziness, they have been successfuly appiled in cluster analysis [19, 20], medical dignosis $[21,22]$ and pattern recognition $[23$, 24].

The constraint of IFS is that the sum of membership degree and non-membership degree is equal to or less than one. However, there are situations where the sum of membership and non-membership degrees is greater than the one with their square sum is equal to or less than one. For instance, a possible attribute value provided by a decision maker maybe $(0.7,0.6)$, in which 0.7 is the membership degree and 0.6 is the non-membership degree respectively. As $0.7+0.6=$ $1.3>1$, the ordered pair $(0.7,0.6)$ is not valid for IFNs. To effectively cope with this circumstance, Yager [25] proposed PFS, where the sum of membership degree and non-membership degree is allowed to be greater than one with their square sum being equal or less than one. From the definition of PFS, we can find that PFS can be viewed as a generalized IFS, and IFS can be viewed as a special case of PFS. Therefore, PFS is more useful and can express more information than IFS. Since the introduction of PFS, quite a few successful applications in decision making have been studied and reported. For example, Peng and Dai [26] proposed several novel Pythagorean fuzzy stochastic multi-attribute decision making methods based on prospect theory and regret theory. Wei [27] proposed new operations for Pythagorean fuzzy numbers (PFNs), which can deal with the interrelationship between Pythagorean fuzzy membership and non-membership degrees. Muhammad et al. [28] extended the TOPSIS (technique for order preference by similarity to ideal solution) to decision making with interval-valued Pythagorean fuzzy information based on Choquet integral. Wei et al. [29], Geng et al. [30], and Liu et al. [31] investigated decision making problems with Pythagorean 2-tuple linguistic information and Pythagorean fuzzy uncertain linguistic information respectively. More contributions about PFSs in decision making can be found in literatures [32-36].

As the complexity in real decision-making problems is increasing, we have to consider the following questions. First there are circumstances where the sum and square sum of membership and nonmembership degrees are greater than one. For example, a decision maker may provide 0.7 and 0.8 as the membership and non-membership degrees respectively. Evidently, the ordered pair $(0.7,0.8)$ cannot be represented by IFNs or PFNs. Therefore, the fuzzy set theory should be extended to accommodate new circumstances. Second in most real decision-making problems, attributes are related which means the interrelationship between attributes should be considered. Therefore, we should aggregate the attribute values as well we their interrelationship to obtain the overall values for alternatives. To address the first issue, Yager [37] proposed the concept of $q$-ROFS. The $q$-ROFSs are also characterized by a membership degree and a non-membership degree, satisfying that the $q$ th power of membership degree and $q$ th power of the degree non-membership are less than or equal to 1 . Obviously, $q$-ROFS relaxes the constraints of both IFS and PFS, and provides more freedom for decision makers. Moreover, the space of uncertain information that $q$-ROFSs can describe is broader than both IFSs and PFSs. In other words, all intuitionistic fuzzy membership degrees and Pythagorean fuzzy membership degrees are part of $q$-rung orthopair fuzzy membership degrees. By adjusting the parameter $q$ in $q$-ROFS, the information expression range can be determined. Thus, $q$-ROFSs exhibit more usefulness and powerfulness than IFSs and PFSs. Furthermore, Liu and Wang [38] introduced simple weighted averaging operators for aggregating $q$-rung orthopair fuzzy information. For the second issue, Bonferroni [39], Sykora [40], Maclaurin [41], and Muirhead [42] proposed the Bonferroni mean (BM), Heronian mean (HM), Maclaurin symmetric mean (MSM), and Muirhead mean (MM) respectively. All the aggregation technologies can capture the interrelationship between aggregated arguments. Recently, P.D. Liu and J.L. Liu [43] investigated the $\mathrm{BM}$ in $q$-ROFSs and proposed a family of $q$-rung orthopair fuzzy Bonferroni mean operators. Liu and Wang [44] developed some novel $q$-rung orthopair fuzzy Bonferroni mean operators based on Archimedean t-norm and t-conorm. Wei et al. [45] developed series of $q$-rung orthopair fuzzy Heronian mean operators. More recently, Liu and $\mathrm{Li}$ [46] pointed out that as $\mathrm{BM}$ and $\mathrm{HM}$ only consider the interrelationship 
between any two arguments while MM can catch the interrelationship among all arguments, MM has advantages over BM and HM. Moreover, MSM is a special case of MM, which means MM is more general than MSM. In addition, MM has a parameter of vector, leading to a flexible aggregation process. Thus, considering the advantages of MM, we should utilize MM to aggregate $q$-rung orthopair fuzzy numbers ( $q$-ROFNs).

The motivations and goals of this paper are (1) to propose novel aggregation operators to aggregate $q$ ROFNs based on MM; (2) to introduce a novel approach to MAGDM based on the proposed method. We also demonstrate the advantages of the proposed operators and method. In order to do this, the remainder of this paper is organized as follows. Section 2 briefly recalls basic concepts such as the $q$-ROFS and the MM. In Section 3, we develop new $q$-rung orthopair fuzzy aggregation operators, such as the $q$ rung orthopair fuzzy Muirhead mean ( $q$-ROFMM) operator, the $q$-rung orthopair fuzzy weighted Muirhead mean ( $q$-ROFWMM) operator, the $q$-rung orthopair fuzzy dual Muirhead mean ( $q$-ROFDMM) operator and the $q$-rung orthopair fuzzy weighted dual Muirhead mean (q-ROFWDMM) operator. In addition, we discuss some desirable properties and special cases of the proposed operators. In Section 4, we introduce a novel method to MAGDM problems based on the proposed operators. In Section 5, a numerical instance is provided to show the validity and superiority of the proposed method. The conclusions are given in Section 6.

\section{Basic concepts}

In this section, we briefly recall some basic notions such as $q$-ROFS and MM.

\subsection{The q-rung orthopair fuzzy set}

Definition 1 [29]. Let $X$ be an ordinary set, then a $q$ ROFS $A$ is defined as follows:

$$
A=\left\{\left\langle x, u_{A}(x), v_{A}(x)\right\rangle \mid x \in X\right\},
$$

where $u_{A}(x)$ and $v_{A}(x)$ denote the membership and non-membership degrees respectively, satisfying $\quad 0 \leq u_{A}(x) \leq 1 \quad, \quad 0 \leq v_{A}(x) \leq 1 \quad$ and

$$
0 \leq u_{A}(x)^{q}+v_{A}(x)^{q} \leq 1 \quad, \quad(q \geq 1) \quad \text {. Then }
$$

$\pi_{A}(x)=\left(u_{A}(x)^{q}+v_{A}(x)^{q}-u_{A}(x)^{q} v_{A}(x)^{q}\right)^{1 / q}$ is the degree of indeterminacy. Liu and Wang [30] called $\left(u_{A}(x), v_{A}(x)\right)$ a $q$-ROFN, which can be denoted as $a=(u, v)$.

In addition, Liu and Wang [30] proposed some operations for $q$-ROFNs.

Definition 2 [30]. Let $a_{1}=\left(u_{1}, v_{1}\right)$ and $a_{2}=\left(u_{2}, v_{2}\right)$ be two $q$-ROFNs, $\lambda$ be a positive real number, then

(1) $a_{1} \oplus a_{2}=\left(\left(u_{1}^{q}+u_{2}^{q}-u_{1}^{q} u_{2}^{q}\right)^{1 / q}, v_{1} v_{2}\right)$;

(2) $a_{1} \otimes a_{2}=\left(u_{1} u_{2},\left(v_{1}^{q}+v_{2}^{q}-v_{1}^{q} v_{2}^{q}\right)^{1 / q}\right)$;

(3) $\lambda a_{1}=\left(\left(1-\left(1-u_{1}^{q}\right)^{\lambda}\right)^{1 / q}, v_{1}^{\lambda}\right)$;

(4) $a_{1}^{\lambda}=\left(u_{1}^{\lambda},\left(1-\left(1-v_{1}^{q}\right)^{\lambda}\right)^{1 / q}\right)$.

Moreover, Liu and Wang [30] proposed a comparison law to compare any two $q$-ROFNs.

Definition 3 [30]. Let $a=(u, v)$ be a $q$-ROFN, then the score function of $a$ is defined as $S(a)=u^{q}-v^{q}$, the accuracy function of $a$ is defined as $H(a)=u^{q}+v^{q}$. Let $a_{1}=\left(u_{1}, v_{1}\right)$ and $a_{2}=\left(u_{2}, v_{2}\right)$ be any two $q$-ROFNs, $S\left(a_{1}\right)$ and $S\left(a_{2}\right)$ be the score functions of $a_{1}$ and $a_{2}$ respectively, $H\left(a_{1}\right)$ and $H\left(a_{2}\right)$ be the accuracy functions of $a_{1}$ and $a_{2}$ respectively, then

(1) if $S\left(a_{1}\right)>S\left(a_{2}\right)$, then $a_{1}>a_{2}$;

(2) if $S\left(a_{1}\right)=S\left(a_{2}\right)$, then

$$
\begin{aligned}
& \text { if } H\left(a_{1}\right)>H\left(a_{2}\right) \text {, then } a_{1}>a_{2} \text {; } \\
& \text { if } H\left(a_{1}\right)=H\left(a_{2}\right) \text {, then } a_{1}=a_{2} \text {. }
\end{aligned}
$$

\subsection{Muirhead mean}

The MM was firstly proposed by Muirhead [34] for crisp numbers. The prominent characteristic of MM is that the interrelationship between aggregated arguments can be captured. 
Definition 4 [34]. Let $a_{j}(j=1,2, \ldots, n)$ be a collection of crisp numbers and $P=\left(p_{1}, p_{2}, \ldots, p_{n}\right) \in R^{n}$ be a vector of parameters. Then, the MM is defined as

$$
M^{P}\left(a_{1}, a_{2}, \ldots, a_{n}\right)=\left(\frac{1}{n !} \sum_{\vartheta \in S_{n}} \prod_{j=1}^{n} a_{\vartheta(j)}^{P_{j}}\right)^{\frac{1}{\sum_{j=1}^{n} P_{j}}},
$$

where $\vartheta(j)(j=1,2, \ldots, n)$ is any permutation of $(1$, $2, \ldots, n)$, and $S_{n}$ is the collection of all permutations of $(1,2, \ldots, n)$.

Furthermore, Liu and Li [36] proposed the dual Muirhead mean (DMM)

Definition 5 [36]. Let $a_{j}(j=1,2, \ldots, n)$ be a collection of crisp numbers and $P=\left(p_{1}, p_{2}, \ldots, p_{n}\right) \in R^{n}$ be a vector of parameters. Then, the MM is defined as $\operatorname{DMM}^{P}\left(a_{1}, a_{2}, \ldots, a_{n}\right)=$

$$
\frac{1}{\sum_{j=1}^{n} p_{j}}\left(\prod_{\vartheta \in S_{n}} \sum_{j=1}^{n}\left(p_{j} a_{\vartheta(j)}\right)\right)^{\frac{1}{n !}},
$$

where $\vartheta(j)(j=1,2, \ldots, n)$ is any permutation of $(1,2, \ldots, n)$, and $S_{n}$ is the collection of all permutations of $(1,2, \ldots, n)$.

\section{3. $q$-Rung orthopair Muirhead mean operators}

In this section, we extend the MM to $q$-rung orthopair fuzzy environment and propose a family of $q$ rung orthopair fuzzy Muirhead mean operators. Moreover, some desirable properties and special cases of the proposed aggregation operators are studied.

\subsection{The q-rung orthopair fuzzy Muirhead mean (q- ROFMM) operator}

Definition 6. Let $a_{j}=\left(u_{j}, v_{j}\right)(j=1,2, \ldots, n)$ be a collection of $q$-ROFNs, $P=\left(p_{1}, p_{2}, \ldots, p_{n}\right) \in R^{n}$ be a vector of parameters, then the $q$-rung orthopair fuzzy Muirhead mean ( $q$-ROFMM) operator is defined as

$$
\begin{aligned}
q-\operatorname{ROFMM}^{P}\left(a_{1}, a_{2}, \ldots, a_{n}\right) & = \\
& \left(\frac{1}{n !} \sum_{\vartheta \in S_{n}} \prod_{j=1}^{n} a_{\vartheta(j)}^{p_{j}}\right)^{\frac{1}{\sum_{j=1}^{n} P_{j}}},
\end{aligned}
$$

where $\vartheta(j)(j=1,2, \ldots, n)$ is any permutation of $(1$, $2, \ldots, n)$, and $S_{n}$ is the collection of all permutations of $(1,2, \ldots, n)$.

According to the operations for $q$-ROFNs, the following theorem can be derived.

Theorem 1. Let $a_{j}=\left(u_{j}, v_{j}\right)(j=1,2, \ldots, n)$ be a collection of $q$-ROFNs, $P=\left(p_{1}, p_{2}, \ldots, p_{n}\right) \in R^{n}$ be a vector of parameters, then aggregated value by the $q$ ROFMM operator is still a $q$-ROFN and

$$
\begin{aligned}
& q-\operatorname{ROFMM}\left(a_{1}, a_{2}, \ldots, a_{n}\right)= \\
& \left(\left(1-\left(\prod_{\vartheta \in S_{n}}\left(1-\prod_{j=1}^{n} u_{\vartheta(j)}^{q p_{j}}\right)\right)^{\frac{1}{n !}}\right)^{1 / q}\right)^{\frac{1}{\sum_{j=1}^{n} P_{j}}}, \\
& \left.\left(1-\left(1-\left(\prod_{\vartheta \in S_{n}}\left(1-\prod_{j=1}^{n}\left(1-v_{\vartheta(j)}^{q}\right)^{p_{j}}\right)\right)^{\frac{1}{n !}}\right)^{\frac{1}{\sum_{j=1}^{n} P_{j}}}\right)^{1 / q}\right) .
\end{aligned}
$$

Proof. According to Definition 2, we have

$$
\begin{gathered}
a_{\vartheta(j)}^{p_{j}}=\left(u_{\vartheta(j)}^{p_{j}},\left(1-\left(1-v_{\vartheta(j)}^{q}\right)^{p_{j}}\right)^{1 / q}\right), \\
\prod_{j=1}^{n} a_{\vartheta(j)}^{p_{j}}=\left(\prod_{j=1}^{n} u_{\vartheta(j)}^{p_{j}},\left(1-\prod_{j=1}^{n}\left(1-v_{\vartheta(j)}^{q}\right)^{p_{j}}\right)^{1 / q}\right) .
\end{gathered}
$$

Therefore,

$$
\begin{aligned}
\sum_{\vartheta \in S_{n}}^{n} \prod_{j=1}^{n} a_{\vartheta(j)}^{p_{j}}=\left(\left(1-\prod_{\vartheta \in S_{n}}\left(1-\prod_{j=1}^{n} u_{\vartheta(j)}^{q p_{j}}\right)\right)^{1 / q},\right. \\
\left.\qquad \prod_{\vartheta \in S_{n}}\left(1-\prod_{j=1}^{n}\left(1-v_{\vartheta(j)}^{q}\right)^{p_{j}}\right)^{1 / q}\right),
\end{aligned}
$$

and

$$
\begin{aligned}
&\left(\frac{1}{n !} \sum_{\vartheta \in S_{n}} \prod_{j=1}^{n} a_{\vartheta(j)}^{p_{j}}\right)^{\frac{1}{\sum_{j=1}^{n} P_{j}}}= \\
&\left(\left(\left(1-\left(\prod_{\vartheta \in S_{n}}\left(1-\prod_{j=1}^{n} u_{\vartheta(j)}^{q p_{j}}\right)\right)^{\left.\left.\frac{1}{n !}\right)^{1 / q}\right)^{\frac{1}{\sum_{j=1}^{n} P_{j}}},}\right.\right.\right.
\end{aligned}
$$




$$
\left(\prod_{\vartheta \in S_{n}}\left(1-\prod_{j=1}^{n}\left(1-v_{\vartheta(j)}^{q}\right)^{p_{j}}\right)^{1 / q}\right)^{\frac{1}{n !}} .
$$

Thus,

$$
\begin{aligned}
& \left(\frac{1}{n !} \sum_{\vartheta \in S_{n}} \prod_{j=1}^{n} a_{\vartheta(j)}^{p_{j}}\right)^{\frac{1}{\sum_{j=1}^{n} P_{j}}}= \\
& \int\left(\left(1-\left(\prod_{\vartheta \in S_{n}}\left(1-\prod_{j=1}^{n} u_{\vartheta(j)}^{q p_{j}}\right)\right)^{\frac{1}{n !}}\right)^{1 / q}\right)^{\frac{1}{\sum_{j=1}^{n} P_{j}}}, \\
& \left.\left(1-\left(1-\left(\prod_{\vartheta \in S_{n}}\left(1-\prod_{j=1}^{n}\left(1-v_{\vartheta(j)}^{q}\right)^{p_{j}}\right)\right)^{\frac{1}{n !}}\right)^{\frac{1}{\sum_{j=1}^{n} P_{j}}}\right)^{1 / q}\right) .
\end{aligned}
$$

Further, let

$$
u=\left(\left(1-\left(\prod_{\vartheta \in S_{n}}\left(1-\prod_{j=1}^{n} u_{\vartheta(j)}^{q p_{j}}\right)\right)^{\frac{1}{n !}}\right)^{1 / q}\right)^{\frac{1}{\sum_{j=1}^{n} P_{j}}},
$$

and

$$
\left.v=\left(1-\left(1-\left(\prod_{\vartheta \in S_{n}}\left(1-\prod_{j=1}^{n}\left(1-v_{\vartheta(j)}^{q}\right)\right)^{p_{j}}\right)\right)^{\frac{1}{n !}}\right)^{\frac{1}{\sum_{j=1}^{n} P_{j}}}\right)^{1 / q} .
$$

It is easy to prove that $0 \leq u \leq 1$ and $0 \leq v \leq 1$. Since $u_{\vartheta(j)}^{q}+v_{\vartheta(j)}^{q} \leq 1$, then $u_{\vartheta(j)}^{q} \leq 1-v_{\vartheta(j)}^{q}$, we can get

$$
\begin{aligned}
u^{q}+v^{q}= & \left(1-\left(\prod_{\vartheta \in S_{n}}\left(1-\prod_{j=1}^{n} u_{\vartheta(j)}^{q p_{j}}\right)\right)^{\frac{1}{n !}}\right)^{\frac{1}{\sum_{j=1}^{n} P_{j}}}+ \\
1- & \left(1-\left(\prod_{\vartheta \in S_{n}}\left(1-\prod_{j=1}^{n}\left(1-v_{\vartheta(j)}^{q}\right)^{p_{j}}\right)\right)^{\left.\frac{1}{n !}\right)^{\frac{1}{\sum_{j=1}^{n} P_{j}}} \leq}\right. \\
& \left(1-\prod_{\vartheta \in S_{n}}\left(1-\prod_{j=1}^{n}\left(1-v_{\vartheta(j)}^{q}\right)^{p_{j}}\right)^{\frac{1}{n !}}\right)^{\frac{1}{\sum_{j=1}^{n} P_{j}}}
\end{aligned}
$$

$$
1-\left(1-\prod_{\vartheta \in S_{n}}\left(1-\prod_{j=1}^{n}\left(1-v_{\vartheta(j)}^{q}\right)^{p_{j}}\right)^{\left.\frac{1}{n !}\right)^{\frac{1}{\sum_{j=1}^{n} P_{j}}}}=1\right.
$$

which means the aggregated value by the $q$-ROFMM operator is also a $q$-ROFN. Therefore, the proof of Theorem 1 is completed.

The prominent advantage of the $q$-ROFMM operator is that it can capture the interrelationship between $q$-ROFNs. In addition, the $q$-ROFMM operator has a parameter vector which leads to a flexible aggregation process. Moreover, quite a few existing operators are special cases of the $q$-ROFMM operator. In the following, we will discuss some special cases of $q$-ROFMM operator regarding to the parameter vector $P$.

Case 1: when $P=(1,0, \ldots, 0)$, then the $q$-ROFMM operator reduces to the following

$$
\begin{aligned}
& q-\operatorname{ROFMM}^{(1,0, \ldots, 0)}\left(a_{1}, a_{2}, \ldots, a_{n}\right)= \\
& \qquad\left(\left(1-\prod_{j=1}^{n}\left(1-u_{j}^{q}\right)^{1 / n}\right)^{1 / q}, \prod_{j=1}^{n} v_{j}^{1 / n}\right)=\frac{1}{n} \sum_{j=1}^{n} a_{j},(6)
\end{aligned}
$$

which is the $q$-rung orthopair fuzzy arithmetic averaging ( $q$-ROFA) operator.

Case 2: when $P=(\lambda, 0, \ldots, 0)$, then the $q$-ROFMM operator reduces to the following

$$
\begin{aligned}
& q-\operatorname{ROFMM}^{(\lambda, 0, \ldots, 0)}\left(a_{1}, a_{2}, \ldots, a_{n}\right)= \\
& \left(\left(1-\left(1-\left(1-\prod_{j=1}^{n}\left(1-\mu_{j}^{\lambda}\right)\right)\right)^{\lambda}\right)^{1 /(q \lambda)},\right. \\
& \left.\left(1-\left(1-\prod_{j=1}^{n}\left(1-\left(1-v_{j}^{q}\right)^{\lambda}\right)^{\lambda}\right)^{1 / \lambda}\right)^{1 / q}\right)=\left(\frac{1}{n} \sum_{j=1}^{n} a_{j}^{\lambda}\right)^{1 / \lambda},
\end{aligned}
$$

which is $q$-rung orthopair fuzzy generalized arithmetic averaging ( $q$-ROFGA) operator.

Case 3: when $P=(1,1,0, \ldots, 0)$, then the $q$-ROFMM operator reduces to the following

$$
\begin{aligned}
& q-\operatorname{ROFMM}^{(1,1,0, \ldots, 0)}\left(a_{1}, a_{2}, \ldots, a_{n}\right)= \\
& \left(\left(1-\left(\prod_{\substack{i, j=1 \\
i \neq j}}^{n}\left(1-\left(u_{i} u_{j}\right)^{q}\right)\right)^{\frac{1}{n(n-1)}}\right)^{\frac{1}{2 q}},\right.
\end{aligned}
$$




$$
\begin{aligned}
\left.\left(1-\left(1-\left(\prod_{\substack{i, j=1 \\
i \neq j}}^{n}\left(v_{i}^{q}+v_{j}^{q}-v_{i}^{q} v_{j}^{q}\right)\right)^{\frac{1}{n(n-1)}}\right)^{\frac{1}{2}}\right)^{\frac{1}{q}}\right) \\
=\left(\frac{1}{n(n-1)} \sum_{\substack{i, j=1 \\
i \neq j}}^{n} a_{i} a_{j}\right)^{1 / 2},
\end{aligned}
$$

which is the $q$-rung orthopair fuzzy Bonferroni mean $(q$-ROFBM) proposed by P.D. Liu and J.L. Liu [35].

Case 4: when $P=\overbrace{(1,1, \ldots, 1,1, \overbrace{0,0, \ldots, 0)}^{n-k}}^{k}$, then the $q$ ROFMM operator reduces to the following $q-$ ROFMM $^{\stackrel{{ }_{1,1, \ldots, 1,0,0, \ldots, 0)}^{k}}{n-k}}\left(a_{1}, a_{2}, \ldots, a_{n}\right)=$

$$
\begin{gathered}
\left(\left(1-\left(1-\left(1-\prod_{j=1}^{n}\left(1-\left(\prod_{j=1}^{n} \mu_{i_{j}}\right)^{q}\right)\right)\right)^{\frac{1}{c_{n}^{k}}}\right)^{1 / q k},\right. \\
\left.\left(1-\left(1-\prod_{j=1}^{n}\left(1-\prod_{j=1}^{n}\left(1-v_{i_{j}}\right)\right)^{\frac{1}{C_{n}^{k}}}\right)^{1 / k}\right)^{1 / q}\right)^{1 / q} \\
=\left(\frac{\underset{1 \leq i_{1}<\ldots i_{k} \leq n}{\bigotimes_{j=1}^{n}} a_{i_{j}}}{C_{n}^{k}}\right)^{1 / k},
\end{gathered}
$$

which is the $q$-rung orthopair fuzzy Maclaurin symmetric mean $(q$-ROFMSM) operator.

Case 5: when $P=(1,1, \ldots, 1)$, then the $q$-ROFMM operator reduces to the following

$q-\operatorname{ROFMM}^{(1,1, \ldots, 1)}\left(a_{1}, a_{2}, \ldots, a_{n}\right)=$

$$
\left(\prod_{j=1}^{n} u_{j}^{1 / n},\left(1-\prod_{j=1}^{n}\left(1-v_{j}^{q}\right)^{1 / n}\right)^{1 / q}\right)=\prod_{j=1}^{n} a_{j}^{1 / n},
$$

which is the $q$-rung orthopair fuzzy geometric averaging ( $q$-ROFG) operator.

Case 6: when $P=(1 / n, 1 / n, \ldots, 1 / n)$, then the $q$ ROFMM operator reduces to the following $q-\operatorname{ROFMM}^{(1,1, \ldots, 1)}\left(a_{1}, a_{2}, \ldots, a_{n}\right)=$

$$
\left(\prod_{j=1}^{n} u_{j}^{1 / n},\left(1-\prod_{j=1}^{n}\left(1-v_{j}^{q}\right)^{1 / n}\right)^{1 / q}\right)=\prod_{j=1}^{n} a_{j}^{1 / n},
$$

which is the $q$-ROFG operator.

Case 7: when $q=2$, then the $q$-ROFMM reduces to the following

$$
\begin{aligned}
& q-\operatorname{ROFMM}^{P}\left(a_{1}, a_{2}, \ldots, a_{n}\right)= \\
& \left(\sqrt{\left.1-\left(\prod_{\vartheta \in S_{n}}\left(1-\left(\prod_{j=1}^{n} u_{\vartheta(j)}^{p_{j}}\right)^{2}\right)\right)^{\frac{1}{n !}}\right)^{\frac{1}{n} \sum_{j=1}^{n} P_{j}}},\right. \\
& \left.\sqrt{1-\left(1-\left(\prod_{\vartheta \in S_{n}}\left(1-\prod_{j=1}^{n}\left(1-v_{\vartheta(j)}^{2}\right)^{p_{j}}\right)\right)^{\frac{1}{n !}}\right)^{\frac{1}{\sum_{j=1}^{n}} P_{j}}}\right),
\end{aligned}
$$

which is the Pythagorean fuzzy Muirhead mean (PFMM) operator.

Case 8: when $q=1$, then the $q$-ROFMM operator reduces to the following

$$
\begin{gathered}
q-\operatorname{ROFMM}^{P}\left(a_{1}, a_{2}, \ldots, a_{n}\right)= \\
\left(\left(1-\left(\prod_{\vartheta \in S_{n}}\left(1-\prod_{j=1}^{n} u_{\vartheta(j)}^{p_{j}}\right)\right)\right)^{\frac{1}{n !}}\right)^{\frac{1}{n} \sum_{j=1}^{p_{j}}}, \\
\left.1-\left(1-\left(\prod\left(1-\prod_{j=1}^{n}\left(1-v_{\vartheta(j)}\right)^{p_{j}}\right)\right)^{\frac{1}{n !}}\right)^{\frac{1}{n} p_{j=1}^{n}}\right),
\end{gathered}
$$

which is the intuitionistic fuzzy Muirhead mean (IFMM) proposed by Liu and Li [36].

It is easy to prove that $q$-ROFMM has the following properties.

\section{Theorem 2 (Idempotency).}

Let $a_{j}=\left(u_{j}, v_{j}\right)(j=1,2, \ldots, n)$ be a collection of $q$ ROFNs, if all the $q$-ROFNs are equal, i.e. $a_{j}=a=(u, v)$, then

$$
q-\operatorname{ROFMM}^{P}\left(a_{1}, a_{2}, \ldots, a_{n}\right)=a .
$$

\section{Theorem 3 (Monotonicity).}


Let $a_{j}=\left(u_{j}, v_{j}\right)$ and $\tilde{b}_{j}=\left(s_{j}, t_{j}\right)(j=1,2, \ldots, n)$ be two collections of $q$-ROFNs. If $u_{j} \geq s_{j}$ and $v_{j} \leq t_{j}$ for all $i$, then

$$
\begin{aligned}
q-\operatorname{ROFMM}^{P}\left(a_{1}, a_{2}, \ldots, a_{n}\right) \\
\\
\geq q-\operatorname{ROFMM}^{P}\left(\tilde{b}_{1}, \tilde{b}_{2}, \ldots, \tilde{b}_{n}\right) .
\end{aligned}
$$

\section{Theorem 4. (Boundedness).}

Let $a_{j}=\left(u_{j}, v_{j}\right)(j=1,2, \ldots, n)$ be a collection of $q$ ROFNs, then

$$
a^{-} \leq q-\operatorname{ROFMM}^{P}\left(a_{1}, a_{2}, \ldots, a_{n}\right) \leq a^{+},
$$

where

$$
\begin{aligned}
& a^{+}=\left(\max _{j=1}^{n}\left(u_{j}\right), \min _{j=1}^{n}\left(v_{j}\right)\right), \\
& a^{-}=\left(\min _{j=1}^{n}\left(u_{j}\right), \max _{j=1}^{n}\left(v_{j}\right)\right) .
\end{aligned}
$$

3.2. The q-rung orthopair fuzzy weighted Muirhead mean (q-ROFWMM) operator

The advantage of the $q$-ROFMM is that it considers the interrelationship between the aggregated $q$ ROFNs. However, the $q$-ROFMM does not consider the self-importance of the aggregated arguments. Therefore, we introduce the $q$-ROFWMM, which can take the corresponding weights of aggregated qROFNs into consideration

Definition 7. Let $a_{j}=\left(u_{j}, v_{j}\right)(j=1,2, \ldots, n)$ be a collection of $q$-ROFNs, $w=\left(w_{1}, w_{2}, \ldots, w_{n}\right)^{T}$ be the weight vector of $a_{j}(j=1,2, \ldots, n)$, satisfying $\quad w_{i} \in[0,1] \quad$ and $\quad \sum_{i=1}^{n} w_{i}=1 \quad, \quad$ and let $P=\left(p_{1}, p_{2}, \ldots, p_{n}\right) \in R^{n}$ be a vector of parameters. If

$$
\begin{aligned}
q-\operatorname{ROFWMM}^{P} & \left(a_{1}, a_{2}, \ldots, a_{n}\right) \\
& \left.=\left(\frac{1}{n !} \sum_{\vartheta \in S_{n}} \prod_{j=1}^{n}\left(n w_{\vartheta(j)} a_{\vartheta(j)}\right)\right)^{p_{j}}\right)_{j=1}^{\frac{1}{n} P_{j}},
\end{aligned}
$$

then $q-$ ROFWMM ${ }^{P}$ is the $q$-ROFWMM, where $\vartheta(j)(j=1,2, \ldots, n)$ is any permutation of $(1,2, \ldots, n)$, and $S_{n}$ is the collection of all permutations of $(1,2, \ldots, n)$.
According to operations of $q$-ROFNs, the aggregated value by the $q$-ROFWMM can be obtained, which is shown as Theorem 5 .

Theorem 5. Let $a_{j}=\left(u_{j}, v_{j}\right)(j=1,2, \ldots, n)$ be a collection of $q$-ROFNs and $P=\left(p_{1}, p_{2}, \ldots, p_{n}\right) \in R^{n}$ be a vector of parameter, then the aggregated value by the $q$-ROFWMM is also a $q$-ROFN and

$q-\operatorname{ROFWMM}^{P}\left(a_{1}, a_{2}, \ldots, a_{n}\right)=$

$$
\begin{aligned}
& \left(\left(1-\left(\prod_{\vartheta \in S_{n}}\left(1-\prod_{j=1}^{n}\left(1-\left(1-u_{\vartheta(j)}^{q}\right)^{n w_{\vartheta(j)}}\right)^{p_{j}}\right)\right)^{\frac{1}{n !}}\right)^{1 / q}\right)^{\frac{1}{\sum_{j=1}^{n} P_{j}}}, \\
& \left.\left(1-\left(1-\left(\prod_{\vartheta \in S_{n}}\left(1-\prod_{j=1}^{n}\left(1-\left(v_{\vartheta(j)}^{n w_{\vartheta(j)}}\right)^{q}\right)^{p_{j}}\right)\right)^{\frac{1}{n !}}\right)^{\frac{1}{\sum_{j=1}^{n} P_{j}}}\right)^{1 / q}\right)
\end{aligned}
$$

The proof of Theorem 5 is similar to that of Theorem 1. In addition, it is easy to prove that the $q$ ROFMM has properties of monotonicity and boundedness, but doesn't have the property of idempotency.

\subsection{The q-rung orthopair fuzzy dual Muirhead mean (q-ROFDMM) operator}

In this section, we extend DMM to $q$-rung orthopair fuzzy environment and propose the $q$ ROFDMM operator

Definition 8. Let $a_{j}=\left(u_{j}, v_{j}\right)(j=1,2, \ldots, n)$ be a collection of $q$-ROFNs, and $P=\left(p_{1}, p_{2}, \ldots, p_{n}\right) \in R^{n}$ be a vector of parameter, then the $q$-ROFDMM is defined as

$$
\begin{aligned}
\underset{\operatorname{ROFDMM}}{P}\left(a_{1}, a_{2}, \ldots, a_{n}\right) \\
=\frac{1}{\sum_{j=1}^{n} p_{j}}\left(\prod_{\vartheta \in S_{n}} \sum_{j=1}^{n}\left(p_{j} a_{\vartheta(j)}\right)\right)^{\frac{1}{n !},}
\end{aligned}
$$

where $\vartheta(j)(j=1,2, \ldots, n)$ is any permutation of $(1,2, \ldots, n)$, and $S_{n}$ is the collection of all permutations of $(1,2, \ldots, n)$.

Similarly, the following theorem can be obtained according to Definition 2. 
Theorem 6. Let $a_{j}=\left(u_{j}, v_{j}\right)(j=1,2, \ldots, n)$ be a collection of $q$-ROFNs, and $P=\left(p_{1}, p_{2}, \ldots, p_{n}\right) \in R^{n}$ be a vector of parameter, then aggregated value by the $q$ ROFDMM operator is still a $q$-ROFN and

$$
\begin{aligned}
& q\left(\left(1-\left(1-\left(\prod_{\vartheta \in S_{n}}\left(1-\prod_{j=1}^{n}\left(1-u_{\vartheta(j)}^{q}\right)^{p_{j}}\right)\right)^{\frac{1}{n !}}\right)^{\frac{1}{\sum_{j=1}^{n} P_{j}}}\right)^{1 / q},\right. \\
& \left.\left(\left(1-\left(\prod_{\vartheta \in S_{n}}\left(1-\prod_{j=1}^{n} v_{\vartheta(j)}^{q p_{j}}\right)\right)^{\frac{1}{n !}}\right)^{1 / q}\right)^{\frac{1}{\sum_{j=1}^{n} P_{j}}}\right) .
\end{aligned}
$$

The proof of Theorem 8 is similar to that of Theorem 1.

In the followings, we shall discuss some special cases of $q$-ROFDMM regarding of the parameter vector $P$.

Case 1: when $P=(1,0, \ldots, 0)$, then the $q$-ROFDMM operator reduces to the following

$$
\begin{aligned}
& q-\operatorname{ROFDMM}^{(1,0, \ldots, 0)}\left(a_{1}, a_{2}, \ldots, a_{n}\right)= \\
& \left(\prod_{j=1}^{n} u_{j}^{1 / n},\left(1-\prod_{j=1}^{n}\left(1-v_{j}^{q}\right)^{1 / n}\right)^{1 / q}\right)=\prod_{j=1}^{n} a_{j}^{1 / n},
\end{aligned}
$$

which is the $q$-ROFG operator.

Case 2: when $P=(\lambda, 0, \ldots, 0)$, then the $q$-ROFDMM reduces to the following

$$
\begin{gathered}
q-\operatorname{ROFDMM} M^{(\lambda, 0, \ldots, 0)}\left(a_{1}, a_{2}, \ldots, a_{n}\right)= \\
\left(\left(1-\left(1-\prod_{j=1}^{n}\left(1-\left(1-u^{q}\right)^{\lambda}\right)^{1 / n}\right)^{1 / \lambda}\right)^{1 / q},\right. \\
\left.\left(\left(1-\prod_{j=1}^{n}\left(1-\left(v^{\lambda}\right)^{q}\right)^{1 / n}\right)^{1 / q}\right)^{1 / \lambda}\right)=\frac{1}{\lambda}\left(\prod_{j=1}^{n}\left(\lambda a_{j}\right)^{\frac{1}{n}}\right),
\end{gathered}
$$

which is the $q$-rung orthopair fuzzy generalized geometric averaging ( $q$-ROFGG) operator.

Case 3: when $P=(1,1,0, \ldots, 0)$, then the $q$-ROFDMM reduces to the following $q-\operatorname{ROFDM} M^{(1,1,0, \ldots, 0)}\left(a_{1}, a_{2}, \ldots, a_{n}\right)=$

$$
\begin{gathered}
\left(\mid\left(1-\left(1-\left(\prod_{\substack{i, j=1 \\
i \neq j}}^{n}\left(u_{i}^{q}+u_{j}^{q}-u_{i}^{q} u_{j}^{q}\right)\right)^{\frac{1}{n(n-1)}}\right)^{\frac{1}{2}}\right)\right. \\
\left.\left.\left(1-\left(\prod_{\substack{i, j=1 \\
i \neq j}}^{n}\left(1-\left(v_{i} v_{j}\right)^{q}\right)\right)^{\frac{1}{q}}\right)^{\frac{1}{n(n-1)}}\right)^{\frac{1}{2 q}}\right)=\frac{1}{2} \prod_{\substack{i, j=1 \\
i \neq j}}^{n}\left(a_{i} \oplus a_{j}\right)^{\frac{1}{n(n-1)}}
\end{gathered}
$$

which is the $q$-rung orthopair fuzzy geometric Bonferroni mean ( $q$-ROFGBM) operator proposed by P.D. Liu and J.L. Liu [35].

Case 4: when $P=\overbrace{(1,1, \ldots, 1,0,0, \ldots, 0)}^{k}$, then the $q$ ROFDMM reduces to the following

$$
\begin{aligned}
& q-\operatorname{ROFDMM}{ }^{(\overbrace{}^{1,1, \ldots, 1,0,0, \ldots, 0)}}\left(a_{1}, a_{2}, \ldots, a_{n}\right)= \\
& \left(\left(1-\left(1-\prod_{1 \leq i_{1}<\ldots<i_{k} \leq k}\left(1-\prod_{j=1}^{k}\left(1-\mu_{i_{j}}^{q}\right)\right)^{\frac{1}{C_{n}^{k}}}\right)^{\frac{1}{k}}\right)^{1 / q},\right. \\
& \left.\left(1-\prod_{1 \leq i_{1} \prec \ldots<i_{k} \leq k}\left(1-\prod_{j=1}^{k} v_{i_{j}}^{q}\right)^{\frac{1}{C_{n}^{k}}}\right)^{\frac{1}{q k}}\right) \\
& =\frac{1}{k}\left(\underset{1 \leq i_{1} \prec \ldots<i_{k} \leq k}{\otimes}\left(\bigoplus_{j=1}^{k} a_{i_{j}}\right)^{\frac{1}{C_{n}^{k}}}\right),
\end{aligned}
$$

which is the $q$-rung orthopair fuzzy dual Maclaurin symmetric mean ( $q$-ROFDMSM) operator.

Case 5: When $P=(1,1, \ldots, 1)$, then the $q$-ROFDMM reduces to the following

$$
\begin{aligned}
& q-\operatorname{ROFMM} M^{(1,1, \ldots, 1)}\left(a_{1}, a_{2}, \ldots, a_{n}\right)= \\
& \qquad\left(\left(1-\prod_{j=1}^{n}\left(1-u_{j}^{q}\right)^{1 / n}\right)^{1 / q}, \prod_{j=1}^{n} v_{j}^{1 / n}\right)=\frac{1}{n} \sum_{j=1}^{n} a_{j},
\end{aligned}
$$

which is $q$-ROFA operator.

Case 6: when $P=(1 / n, 1 / n, \ldots, 1 / n)$, then the $q$ ROFMM reduces to the following $q-\operatorname{ROFMM}^{(1 / n, 1 / n, \ldots, 1 / n)}\left(a_{1}, a_{2}, \ldots, a_{n}\right)=$ 


$$
\left(\left(1-\prod_{j=1}^{n}\left(1-u_{j}^{q}\right)^{1 / n}\right)^{1 / q}, \prod_{j=1}^{n} v_{j}^{1 / n}\right)=\frac{1}{n} \sum_{j=1}^{n} a_{j},(26)
$$

which is $q$-ROFA operator.

Case 7: when $q=2$, then the $q$-ROFDMM reduces to the following

$q-\operatorname{ROFDMM} M^{P}\left(a_{1}, a_{2}, \ldots, a_{n}\right)$

$$
\begin{gathered}
\left(\left(1-\left(1-\prod_{\vartheta \in S_{n}}\left(1-\prod_{j=1}^{n}\left(1-\mu_{\vartheta(j)}^{2}\right)^{r_{j}}\right)^{\frac{1}{n !}}\right)^{\frac{1}{\sum_{j=1}^{n} r_{j}}}\right)^{\frac{1}{2}},\right. \\
\left(1-\prod_{\vartheta \in S_{n}}\left(1-\prod_{j=1}^{n} v_{\vartheta(j)}^{2 r_{j}}\right)^{\frac{1}{n !}}\right),
\end{gathered}
$$

which is the Pythagorean fuzzy dual Muirhead mean (PFDMM) operator.

Case 8: when $q=1$, then the $q$-ROFDMM reduces to the following

$$
\begin{aligned}
& q-\operatorname{ROFDMM}^{P}\left(a_{1}, a_{2}, \ldots, a_{n}\right)= \\
& \left.\qquad 1-\prod_{\vartheta \in S_{n}}\left(1-\prod_{j=1}^{n}\left(1-u_{\vartheta(j)}\right)^{p_{j}}\right)^{\frac{1}{n !}}\right)^{\frac{1}{n} p_{j}}, \\
& \left.\left(1-\left(\prod_{\vartheta \in S_{n}}\left(1-\prod_{j=1}^{n} v_{\vartheta}^{p_{j}}\right)\right)^{\frac{1}{n !}}\right)^{\frac{1}{\sum_{j=1}^{n} p_{j}}}\right) .
\end{aligned}
$$

where the intuitionistic fuzzy dual Muirhead mean (IFDMM) operator is proposed by Liu and Li [28].

Similarly, $q$-ROFDMM also has the properties of idempotency, monotonicity and boundedness.

\subsection{The q-rung orthopair fuzzy weighted dual Muirhead mean (q-ROFWDMM) operator}

Definition 9. Let $a_{j}=\left(u_{j}, v_{j}\right)(j=1,2, \ldots, n)$ be a collection of $q$-ROFNs, $w=\left(w_{1}, w_{2}, \ldots, w_{n}\right)^{T}$ be the weight vector of $a_{j}(j=1,2, \ldots, n)$, satisfying $\quad w_{i} \in[0,1] \quad$ and $\quad \sum_{i=1}^{n} w_{i}=1 \quad$ and let $P=\left(p_{1}, p_{2}, \ldots, p_{n}\right) \in R^{n}$ be a vector of parameters. If

$$
\begin{aligned}
q-\operatorname{ROFWDMM}^{P} & \left(a_{1}, a_{2}, \ldots, a_{n}\right) \\
& \frac{1}{\sum_{j=1}^{n} p_{j}}\left(\prod_{\vartheta \in S_{n}} \sum_{j=1}^{n}\left(p_{j} a_{\vartheta(j)}^{\left.n w_{g(j)}\right)}\right)\right)^{\frac{1}{n !}},
\end{aligned}
$$

then $q-$ ROFWDMM $M^{P}$ is the $q$-ROFWDMM, where $\vartheta(j)(j=1,2, \ldots, n)$ is any permutation of $(1,2, \ldots, n)$, and $S_{n}$ is the collection of all permutations of $(1,2, \ldots, n)$.

The following theorem can be easily obtained.

Theorem 7. Let $a_{j}=\left(u_{j}, v_{j}\right)(j=1,2, \ldots, n)$ be a collection of $q$-ROFNs and $P=\left(p_{1}, p_{2}, \ldots, p_{n}\right) \in R^{n}$ be a vector of parameters, then the aggregated value by using the $q$-ROFWDMM operator is still a $q$-ROFN and

$$
\begin{aligned}
& q-\operatorname{ROFWDMM}\left(a_{1}, a_{2}, \ldots, a_{n}\right)= \\
& \left(1-\left(1-\prod_{\vartheta \in S_{n}}\left(1-\prod_{j=1}^{n}\left(1-\mu_{\vartheta(j)}^{q q w}\right)^{p_{j}}\right)^{\frac{1}{n !}}\right)^{\frac{1}{n=1} \sum_{j=1}^{n} p_{j}}\right)^{1 / q}, \\
& \left(1-\prod_{\vartheta \in S_{n}}\left(1-\prod_{j=1}^{n}\left(1-\left(1-v_{\vartheta(j)}^{q}\right)^{n w}\right)^{p_{j}}\right)^{\frac{1}{n !}}\right) q_{j=1}^{\frac{1}{q \sum_{j=1}^{n} p_{j}}}
\end{aligned}
$$

Similarly, the $q$-ROFWDMM operator has the properties of monotonicity and boundedness, but doesn't have the property of idempotency.

\section{A novel approach to MAGDM based on the proposed operators}

In this section, we shall apply the proposed aggregation operators to solve MAGDM problems in $q$ rung orthopair fuzzy environment.

\subsection{Description of a typical MAGDM problem with q-rung orthopair fuzzy information}

The $q$-ROFSs are effective tools to describe decision makers' fuzziness, uncertainty and indeterminacy. Therefore, they are widely used in MAGDM 
problems. A typical q-rung orthopair fuzzy MAGDM problem can be described as: Let $X=\left\{x_{1}, x_{2}, \ldots, x_{m}\right\}$ be a collection of alternatives, $G=\left\{G_{1}, G_{2}, \ldots, G_{n}\right\} \quad$ be $n$ attributes and $D=\left\{D_{1}, D_{2}, \ldots, D_{t}\right\}$ be a collection of decision makers. For attribute $G_{j}(j=1,2, \ldots, n)$ of alternative $x_{i}(i=1,2, \ldots, m)$, decision maker $D_{k}$ is required to utilize a $q$-ROFN to express his/her evaluation value, which can be denoted as $a_{i j}^{k}=\left(u_{i j}^{k}, v_{i j}^{k}\right)$. Finally, several $q$-rung orthopair fuzzy decision matrix can be obtained, which can be denoted as $A^{k}=\left(\begin{array}{c}k \\ a_{i j}\end{array}\right)_{m \times n}$. The weights of decision makers are $\lambda=\left(\lambda_{1}, \lambda_{2}, \ldots, \lambda_{t}\right)^{T}$, satisfying $\lambda_{k} \in[0,1](k=1,2, \ldots, t)$ and $\sum_{k=1}^{t} \lambda_{k}=1$. Weight vector of the attributes is $w=\left(w_{1}, w_{2}, \ldots, w_{n}\right)^{T}$, satisfying $w_{j} \in[0,1](k=1,2, \ldots, n)$ and $\sum_{j=1}^{n} w_{j}=1$.

\subsection{An algorithm to q-rung orthopair fuzzy MAGDM problems}

Step 1. In real decision-making problems, attributes can always be classified into two types, the benefit type and the cost type. Therefore, the original decision matrix should be normalized in order to eliminate the impact of different attribute types. We can normalize the decision matrix by the following equation,

$$
a_{i j}^{k}=\left(u_{i j}^{k}, v_{i j}^{k}\right)\left\{\begin{array}{ll}
\left(u_{i j}^{k}, v_{i j}^{k}\right) & G_{j} \in I_{1} \\
\left(v_{i j}^{k}, u_{i j}^{k}\right) & G_{j} \in I_{2}
\end{array},\right.
$$

where $I_{1}$ and $I_{2}$ represent the benefit attribute type and the cost attribute type respectively.

Step 2: Utilize the $q$-ROFWMM operator

$$
a_{i}^{k}=q-\operatorname{ROFWM} M^{P}\left(a_{i 1}^{k}, a_{i 2}^{k}, \ldots, a_{i n}^{k}\right),
$$

or the $q$-ROFWDMM operator

$$
a_{i}^{k}=q-R O F W D M M^{P}\left(a_{i 1}^{k}, a_{i 2}^{k}, \ldots, a_{i n}^{k}\right),
$$

to fuse all attribute values to overall preference value $a_{i}^{k}$ with respect to each alternative for each decision maker.

Step 3. Utilize the $q$-ROFWMM operator

$$
a_{i}=q-\operatorname{ROFWMM}\left(a_{i}^{1}, a_{i}^{2}, \ldots, a_{i}^{t}\right),
$$

or the $q$-ROFWDMM operator

$$
a_{i}=q-\operatorname{ROFWDMM}\left(a_{i}^{1}, a_{i}^{2}, \ldots, a_{i}^{t}\right),
$$

to determine the collective overall preference value $a_{i}(i=1,2, \ldots, m)$.

Step 4. According to Definition 3, calculate the scores and accuracy of the overall preference value $a_{i}(i=1,2, \ldots, m)$.

Step 5. Rank the alternatives.

\section{Numerical example}

To illustrate the validity of the proposed method, we provide a numerical instance, which is adapted from reference [37]. A person wants to invest his/her money to a company and after primary evaluation, there are five possible companies remained on the candidate list, which can be denoted by $X=\left\{x_{1}, x_{2}, x_{3}, x_{4}, x_{5}\right\}$. Three decision makers $D_{k}(k=1,2,3)$, whose weight vector is $\lambda=(0.35,0.40,0.25)^{T}$, are invited to assess the five possible companies from four attributes which are defined as follows: the risk analysis $\left(G_{1}\right)$, the growth analysis $\left(G_{2}\right)$, the social-political impact analysis $\left(G_{3}\right)$, and the environmental impact analysis $\left(G_{4}\right)$. Weight vector of the attributes is $w=(0.2,0.1,0.3,0.4)^{T}$. The decision makers $D_{k}(k=1,2,3)$ are required to evaluate the companies $x_{i}(i=1,2,3,4,5)$ with respect to the attributes $G_{j}(j=1,2,3,4)$ by the $q$-ROFNs. Therefore, three decision matrices $A^{k}=\left(a_{i j}^{k}\right)_{5 \times 4}(k=1,2,3)$ can be obtained, which are shown in Tables 1 to 3 .

Table 1. Intuitionistic fuzzy decision matrix $A^{1}$ provided by $D_{1}$

\begin{tabular}{ccccc}
\hline & $G_{1}$ & $G_{2}$ & $G_{3}$ & $G_{4}$ \\
\hline$x_{1}$ & $(0.5,0.4)$ & $(0.5,0.3)$ & $(0.2,0.6)$ & $(0.4,0.4)$ \\
$x_{2}$ & $(0.7,0.3)$ & $(0.7,0.3)$ & $(0.6,0.2)$ & $(0.6,0.2)$ \\
$x_{3}$ & $(0.5,0.4)$ & $(0.6,0.4)$ & $(0.6,0.2)$ & $(0.5,0.3)$ \\
$x_{4}$ & $(0.8,0.2)$ & $(0.7,0.2)$ & $(0.4,0.2)$ & $(0.5,0.2)$ \\
$x_{5}$ & $(0.4,0.3)$ & $(0.4,0.2)$ & $(0.4,0.5)$ & $(0.4,0.6)$ \\
\hline
\end{tabular}

Table 2. Intuitionistic fuzzy decision matrix $A^{2}$ provided by $D_{2}$

\begin{tabular}{ccccc}
\hline & $G_{1}$ & $G_{2}$ & $G_{3}$ & $G_{4}$ \\
\hline$x_{1}$ & $(0.4,0.5)$ & $(0.6,0.2)$ & $(0.5,0.4)$ & $(0.5,0.5)$ \\
$x_{2}$ & $(0.5,0.4)$ & $(0.6,0.2)$ & $(0.6,0.3)$ & $(0.7,0.3)$ \\
$x_{3}$ & $(0.4,0.5)$ & $(0.3,0.5)$ & $(0.4,0.4)$ & $(0.2,0.6)$ \\
$x_{4}$ & $(0.5,0.4)$ & $(0.7,0.2)$ & $(0.4,0.4)$ & $(0.6,0.2)$
\end{tabular}




\begin{tabular}{|c|c|c|c|c|}
\hline$x_{5}$ & $(0.6,0.3)$ & $(0.7,0.2)$ & $(0.4,0.2)$ & $(0.7,0.2)$ \\
\hline & $G_{1}$ & $G_{2}$ & $G_{3}$ & $G_{4}$ \\
\hline$x_{1}$ & $(0.4,0.5)$ & $(0.6,0.2)$ & $(0.5,0.4)$ & $(0.5,0.5)$ \\
\hline$x_{2}$ & $(0.5,0.4)$ & $(0.6,0.2)$ & $(0.6,0.3)$ & $(0.7,0.3)$ \\
\hline$x_{3}$ & $(0.4,0.5)$ & $(0.3,0.5)$ & $(0.4,0.4)$ & $(0.2,0.6)$ \\
\hline$x_{4}$ & $(0.5,0.4)$ & $(0.7,0.2)$ & $(0.4,0.4)$ & $(0.6,0.2)$ \\
\hline$x_{5}$ & $(0.6,0.3)$ & $(0.7,0.2)$ & $(0.4,0.2)$ & $(0.7,0.2)$ \\
\hline
\end{tabular}

\subsection{The decision-making process}

In the following, we utilize the proposed method to determine the company that the person should invest his/her money to.

Step 1. Normalize the decision-making matrices. As all the attributes are benefit attributes, they do not need to be normalized.

Step 2. For each alternative, aggregate the attribute values provided by decision makers $D_{k}$. Here we utilize the Eq. (32) to aggregate the attribute values and we assume $q=3$ and $P=(1,1,1,1)$. Therefore, we can get

$$
\begin{aligned}
& a_{1}^{1}=(0.7973,0.3148) a_{2}=(0.8857,0.2053) \\
& a_{3}=(0.8488,0.2507) a_{4}=(0.8862,0.1743) \\
& a_{5}^{1}=(0.7810,0.2854) a_{1}^{2}=(0.8313,0.2625) \\
& a_{2}^{2}=(0.8699,0.2364) a_{3}^{2}=(0.7525,0.3680) \\
& a_{4}^{2}=(0.8577,0.2308) a_{5}^{2}=(0.8764,0.1892) \\
& a_{1}^{3}=(0.8175,0.1892) a_{2}^{3}=(0.8626,0.2053) \\
& a_{3}^{3}=(0.7593,0.2725) a_{4}^{3}=(0.8119,0.2474) \\
& a_{5}^{3}=(0.8524,0.2507)
\end{aligned}
$$

Step 3. Calculate the collective preference values by Eq. (34). We assume $q=3$ and $P=(1,1,1,1)$. Thus, we can get

$$
\begin{gathered}
a_{1}=(0.9530,0.1472) \quad a_{2}=(0.9688,0.1257), \\
a_{3}=(0.9464,0.1740) \quad a_{4}=(0.9640,0.1256) \\
a_{5}=(0.9604,0.1399)
\end{gathered}
$$

Step 4. Calculate the scores and accuracy of collective preference values, we have

$$
\begin{gathered}
s\left(a_{1}\right)=0.8622 \quad s\left(a_{2}\right)=0.9073 \quad s\left(a_{3}\right)=0.8425 \\
s\left(a_{4}\right)=0.8940 \quad s\left(a_{5}\right)=0.8830
\end{gathered}
$$

Step 5. Rank the alternatives. According to the scores of the overall assessments of alternatives, the ranking result of corresponding alternatives is $x_{2} \succ x_{4} \succ x_{5} \succ x_{1} \succ x_{3}$. Therefore, $x_{2}$ is the best alternative, which means that the person should invest his/her money to the company $x_{2}$.

In Step 2, if we utilize the $q$-ROFWDMM operator (suppose $q=3$ and $P=(1,1,1,1)$ ) to aggregate decision makers' preference information for each alternative, we can get

$$
\begin{aligned}
& a_{1}^{1}=(0.2917,0.8080) a_{2}=(0.4690,0.7009) \\
& a_{3}^{1}=(0.4021,0.7525) a_{4}=(0.4223,0.6565) \\
& a_{5}^{1}=(0.3071,0.8095) a_{1}^{2}=(0.3680,0.7736) \\
& a_{2}^{2}=(0.4337,0.7365) a_{3}^{2}=(0.2507,0.8313) \\
& a_{4}^{2}=(0.3960,0.7450) a_{5}^{2}=(0.4270,0.6826) \\
& a_{1}^{3}=(0.3538,0.6826) a_{2}^{3}=(0.4162,0.7009) \\
& a_{3}^{3}=(0.2725,0.7593) a_{4}^{3}=(0.3328,0.7623) \\
& a_{5}^{3}=(0.3985,0.7525)
\end{aligned}
$$

Then in Step 3, if we utilize the $q$-ROFWMM operator (suppose $q=3$ and $P=(1,1,1,1)$ ) to calculate the overall preference for each alternative, we can get

$$
\begin{gathered}
a_{1}=(0.2013,0.9371) \quad a_{2}=(0.2680,0.9220) \\
a_{3}=(0.1795,0.9440) \quad a_{4}=(0.2306,0.9262) \\
a_{5}=(0.2255,0.9352)
\end{gathered}
$$

Therefore, the scores of the overall preference are

$$
\begin{gathered}
s\left(a_{1}\right)=-0.8149 \quad s\left(a_{2}\right)=-0.7646 \\
s\left(a_{3}\right)=-0.8355 \quad s\left(a_{4}\right)=-0.7821 \\
s\left(a_{5}\right)=-0.8063
\end{gathered}
$$

Thus, the ranking order of the alternatives is $x_{2} \succ x_{4} \succ x_{5} \succ x_{1} \succ x_{3}$, which means that $x_{2}$ is the best alternative.

In [35], PD. Liu and JL. Liu proved the effectiveness of the method based on $q$-rung orthopair fuzzy weighted Bonferroni mean ( $q$-ROFWBM) operator and the $q$-rung orthopair fuzzy weighted geometric Bonferroni mean ( $q$-ROFWGBM) operator by using some existing methods to solve the same problem. In most of the results, the ranking order is $x_{2} \succ x_{4} \succ x_{5} \succ x_{1} \succ x_{3}$, which is the same as the ranking order using our proposed method. Moreover, the ranking result by utilizing the method in [36] based on the intuitionistic fuzzy weighted Muirhead 
mean (IFWMM) operator and the intuitionistic fuzzy dual weighted Muirhead mean (IFDWMM) operator is also $x_{2} \succ x_{4} \succ x_{5} \succ x_{1} \succ x_{3}$, which also proves the validity of the proposed method in the present paper.

\subsection{The influence of the parameters on the ranking results}

In this section, we shall discuss the influence of the parameters on the results. First of all, we investigate the effect of the parameter $q$ on the final results. Then we discuss the influence of the parameter vector $P$ on the score functions of the overall assessments and the final ranking results. The influence of the parameter $q$ on the results are shown as Figs 1 and 2 .

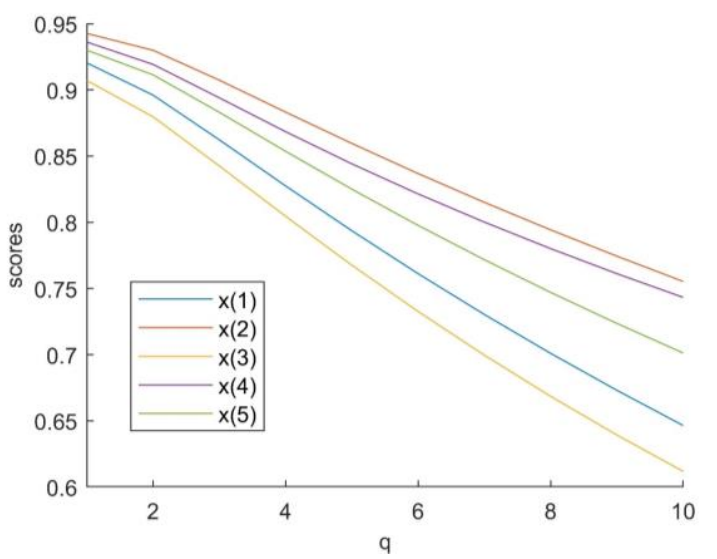

Fig 1. Score values of the alternatives when $q \in[1,10]$ based on the $q$-ROFWMM operator

In Fig 1, we can see that the scores of the overall values are different by assigning different parameters $q$ to the $q$-ROFWMM operator. However, the ranking results are always $x_{2} \succ x_{4} \succ x_{5} \succ x_{1} \succ x_{3}$. In addition, the score functions of the overall assessments by utilizing the $q$-ROFWMM operator become smaller with the parameter $q$ increases. Therefore, the parameter $q$ can be viewed as decision makers' attitude to optimism or pessimism. The more optimistic the decision makers are, the smaller value should be assigned to $q$. The more pessimistic the decision makers are, the greater value should be assigned to $q$.

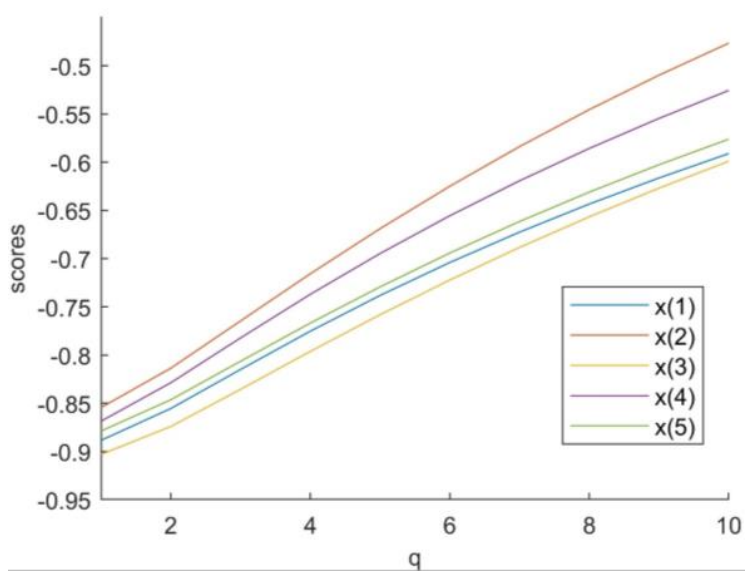

Fig 2. Score values of the alternatives when $q \in[1,10]$ based on the $q$-ROFWDMM operator

In Fig 2, we can find out that with different parameters $q$ in the $q$-ROFWDMM operator, the scores are different. However, no matter what the parameters $q$ are, the ranking results are always $x_{2} \succ x_{4} \succ x_{5} \succ x_{1} \succ x_{3}$, which is the same as the $q$-ROFWMM operator. However, score functions of the overall assessments by utilizing the $q$ ROFWDMM operator become greater with the parameter $q$ increases, which is opposite to the $q$ ROFWMM operator. Therefore, the more optimistic the decision makers are, the greater value should be assigned to $q$. The more pessimistic the decision makers are, the smaller value should be assigned to $q$ in the $q$-ROFWDMM operator.

In the following, we investigate the influence of the parameter vector $P$ on the scores function of the overall assessments and the final ranking results. We assume that $q=3$. Details can be found in Table 4 and 5.

As we can see from Table 4 and 5, the scores of the overall values are different by utilizing different parameter vector $P$. However, the ranking orders are always the same, that is $x_{2} \succ x_{4} \succ x_{5} \succ x_{1} \succ x_{3}$. In addition, some special cases can be obtained by assigning some special parameter vectors to the proposed aggregation operators. For instance, if $P=(1$, $0,0,0)$, then the $q$-ROFWMM operator reduces to the $q$-ROFWA operator and the $q$-ROFWDMM operator reduces to the $q$-ROFWG operator. Moreover, from Table 4 we can find out that the more interrelationship among arguments are taken into account, the greater of the score values of the overall assessments will become by utilizing the $q$-ROFWMM operator. However, the more interrelationship among arguments are taken into consideration, the smaller of the 
score values of the overall assessments will become by utilizing the $q$-ROFWDMM operator. Therefore, different parameter vector $P$ can be regarded as the decision makers' risk preference.

\subsection{Comparative analysis}

In this subsection, the ranking results by utilizing different methods are always $x_{2} \succ x_{4} \succ x_{5} \succ x_{1} \succ x_{3}$. Thus, it cannot show the advantages and superiorities of the proposed method. In this section, we conduct a comparative analysis to illustrate the merits of our method. The example is adapted from [35].
Example. A company hopes to develop a novel career and after primary discussion, there are four possible choices $\left\{x_{1}, x_{2}, x_{3}, x_{4}, x_{5}\right\}$. They are real estate industry, food industry, education industry, and computer industry. In order to select the best choices, the possible alternatives are evaluated from four attributes, they are ability to compete $\left(G_{1}\right)$, ability to grow $\left(G_{2}\right)$, influence of surrounding environment $\left(G_{3}\right)$, and influence of social-politic $\left(G_{4}\right)$. Weight vector of the four attributes is $w=(0.25,0.30,0.35,0.10)^{T}$. Decision makers are

\begin{tabular}{|c|c|c|}
\hline Parameter vector $P$ & The score function $s\left(\alpha_{i}\right)$ & Ranking results \\
\hline$P=(1,0,0,0)$ & $\begin{array}{c}s\left(a_{1}\right)=0.0395, s\left(a_{2}\right)=0.1727, s\left(a_{3}\right)=-0.0110 \\
s\left(a_{4}\right)=0.1347, s\left(a_{5}\right)=0.0977\end{array}$ & $x_{2} \succ x_{4} \succ x_{5} \succ x_{1} \succ x_{3}$ \\
\hline$P=(1,1,0,0)$ & $\begin{array}{c}s\left(a_{1}\right)=0.5419, s\left(a_{2}\right)=0.6698, s\left(a_{3}\right)=0.4937 \\
s\left(a_{4}\right)=0.6322, s\left(a_{5}\right)=0.6015\end{array}$ & $x_{2} \succ x_{4} \succ x_{5} \succ x_{1} \succ x_{3}$ \\
\hline$P=(1,1,1,0)$ & $\begin{array}{c}s\left(a_{1}\right)=0.7660, s\left(a_{2}\right)=0.8395, s\left(a_{3}\right)=0.7353 \\
s\left(a_{4}\right)=0.8178, s\left(a_{5}\right)=0.8001\end{array}$ & $x_{2} \succ x_{4} \succ x_{5} \succ x_{1} \succ x_{3}$ \\
\hline$P=(1,1,1,1)$ & $\begin{array}{c}s\left(a_{1}\right)=0.8622, s\left(a_{2}\right)=0.9073, s\left(a_{3}\right)=0.8425 \\
s\left(a_{4}\right)=0.8940, s\left(a_{5}\right)=0.8830\end{array}$ & $x_{2} \succ x_{4} \succ x_{5} \succ x_{1} \succ x_{3}$ \\
\hline$P=(0.5,0.5,0.5,0.5)$ & $\begin{array}{c}s\left(a_{1}\right)=0.8594, s\left(a_{2}\right)=0.9061, s\left(a_{3}\right)=0.8394 \\
s\left(a_{4}\right)=0.8896, s\left(a_{5}\right)=0.8806\end{array}$ & $x_{2} \succ x_{4} \succ x_{5} \succ x_{1} \succ x_{3}$ \\
\hline$P=(2,0,0,0)$ & $\begin{array}{c}s\left(a_{1}\right)=0.0490, s\left(a_{2}\right)=0.1837, s\left(a_{3}\right)=0.0090 \\
s\left(a_{4}\right)=0.1717, s\left(a_{5}\right)=0.1227\end{array}$ & $x_{2} \succ x_{4} \succ x_{5} \succ x_{1} \succ x_{3}$ \\
\hline
\end{tabular}

Table 5 Ranking results by using the different parameter vector $P$ in the $q$-ROFWDMM operator $(q=3)$

\begin{tabular}{|c|c|c|}
\hline Parameter vector $P$ & The score function $s\left(\alpha_{i}\right)$ & Ranking results \\
\hline$P=(1,0,0,0)$ & $\begin{array}{c}s\left(a_{1}\right)=0.0827, s\left(a_{2}\right)=0.2613, s\left(a_{3}\right)=0.0302 \\
s\left(a_{4}\right)=0.1623, s\left(a_{5}\right)=0.1334\end{array}$ & $x_{2} \succ x_{4} \succ x_{5} \succ x_{1} \succ x_{3}$ \\
\hline$P=(1,1,0,0)$ & $\begin{array}{c}s\left(a_{1}\right)=-0.4252, s\left(a_{2}\right)=-0.2953 s\left(a_{3}\right)=-0.4742 \\
s\left(a_{4}\right)=-0.3472, s\left(a_{5}\right)=-0.4008\end{array}$ & $x_{2} \succ x_{4} \succ x_{5} \succ x_{1} \succ x_{3}$ \\
\hline$P=(1,1,1,0)$ & $\begin{array}{c}s\left(a_{1}\right)=-0.6920, s\left(a_{2}\right)=-0.6123, s\left(a_{3}\right)=-0.7239 \\
s\left(a_{4}\right)=-0.6413, s\left(a_{5}\right)=-0.6782\end{array}$ & $x_{2} \succ x_{4} \succ x_{5} \succ x_{1} \succ x_{3}$ \\
\hline$P=(1,1,1,1)$ & $\begin{array}{c}s\left(a_{1}\right)=-0.8149, s\left(a_{2}\right)=-0.7646, s\left(a_{3}\right)=-0.8355 \\
s\left(a_{4}\right)=-0.7821, s\left(a_{5}\right)=-0.8063\end{array}$ & $x_{2} \succ x_{4} \succ x_{5} \succ x_{1} \succ x_{3}$ \\
\hline$P=(0.5,0.5,0.5,0.5)$ & $s\left(a_{1}\right)=-0.8073, s\left(a_{2}\right)=-0.7603, s\left(a_{3}\right)=-0.8321$ & $x_{2} \succ x_{4} \succ x_{5} \succ x_{1} \succ x_{3}$ \\
\hline
\end{tabular}




$$
\begin{array}{cc}
s\left(a_{4}\right)=-0.7740, s\left(a_{5}\right)=-0.7976 & \\
s\left(a_{1}\right)=0.0594, s\left(a_{2}\right)=0.2539, s\left(a_{3}\right)=0.0135 & \\
s\left(a_{4}\right)=0.1413, s\left(a_{5}\right)=0.1057 & x_{2} \succ x_{4} \succ x_{5} \succ x_{1} \succ x_{3}
\end{array}
$$

required to express their preference information for the industry $x_{i}(i=1,2,3,4)$ with respect to the $G_{j}(j=1,2,3,4,5)$ by $q$-ROFNs. Therefore, a $q$-rung orthopair fuzzy decision matrix can be obtained in Table 6.

In [35], PD. Liu and JL. Liu utilized the methods based on the intuitionistic fuzzy weighted averaging (IFWA) operator proposed by $\mathrm{Xu}$ [4], the weighted veloped by $\mathrm{Xu}$ and Yager [5], the Pythagorean fuzzy weighted geometric (PFWG) proposed by Garg [38], and the $q$-ROFWGBM operator. In the present paper, to illustrate the superiorities of the proposed method comprehensively, we also use the method based on the weighted Pythagorean fuzzy geometric Bonferroni mean (WPFGBM) proposed by Liang et al. [39],

\begin{tabular}{|c|c|c|}
\hline Methods and corresponding aggregation operators & Scores of $s\left(a_{i}\right)$ & Ranking results \\
\hline $\begin{array}{l}\text { Method based on the IFWA operator proposed by } \\
\text { Xu [4] }\end{array}$ & $\begin{array}{c}s\left(a_{1}\right)=0.1768, s\left(a_{2}\right)=0.3036 s\left(a_{3}\right)=-0.1177 \\
s\left(a_{4}\right)=0.2497, s\left(a_{5}\right)=0.3678\end{array}$ & $x_{5} \succ x_{2} \succ x_{4} \succ x_{1} \succ x_{3}$ \\
\hline $\begin{array}{l}\text { Method based on the WIFBM operator proposed } \\
\text { by Xu and Ygaer [5] }\end{array}$ & $\begin{array}{c}s\left(a_{1}\right)=-0.4716, s\left(a_{2}\right)=-0.5559, s\left(a_{3}\right)=-0.6280 \\
s\left(a_{4}\right)=-0.5279, s\left(a_{5}\right)=-0.5093\end{array}$ & $x_{1} \succ x_{5} \succ x_{4} \succ x_{2} \succ x_{3}$ \\
\hline $\begin{array}{l}\text { Method based on the IFWMM operator proposed } \\
\text { by Liu and } \mathrm{Li}[36]\end{array}$ & $\begin{array}{c}s\left(a_{1}\right)=0.7971, s\left(a_{2}\right)=-0.7474, s\left(a_{3}\right)=-0.7185 \\
s\left(a_{4}\right)=-0.7390, s\left(a_{5}\right)=-0.7932\end{array}$ & $x_{1} \succ x_{5} \succ x_{2} \succ x_{4} \succ x_{3}$ \\
\hline $\begin{array}{l}\text { Method based on the IFDWMM operator pro- } \\
\text { posed by Liu and Li [36] }\end{array}$ & $\begin{array}{c}s\left(a_{1}\right)=-0.5374, s\left(a_{2}\right)=-0.6175, s\left(a_{3}\right)=-0.6749 \\
s\left(a_{4}\right)=-0.6302, s\left(a_{5}\right)=-0.5551\end{array}$ & $x_{1} \succ x_{5} \succ x_{2} \succ x_{4} \succ x_{3}$ \\
\hline $\begin{array}{l}\text { Method based on the PFWG operator proposed by } \\
\text { Garg [38] }\end{array}$ & $\begin{array}{c}s\left(a_{1}\right)=0.2822, s\left(a_{2}\right)=0.0775, s\left(a_{3}\right)=-0.0570 \\
s\left(a_{4}\right)=0.1159, s\left(a_{5}\right)=0.2832\end{array}$ & $x_{5} \succ x_{1} \succ x_{4} \succ x_{2} \succ x_{3}$ \\
\hline $\begin{array}{l}\text { Method based on the WPFBGM operator pro- } \\
\text { posed by Liang et al. [39] }\end{array}$ & $\begin{array}{c}s\left(a_{1}\right)=0.7355, s\left(a_{2}\right)=0.6768, s\left(a_{3}\right)=0.6201 \\
s\left(a_{4}\right)=0.6814, s\left(a_{5}\right)=0.7548\end{array}$ & $x_{5} \succ x_{1} \succ x_{4} \succ x_{2} \succ x_{3}$ \\
\hline $\begin{array}{l}\text { Method based on the } q \text {-ROFWGBM operator } \\
\text { proposed by PD. Liu and JL. Liu [35] }\end{array}$ & $\begin{array}{c}s\left(a_{1}\right)=0.5940, s\left(a_{2}\right)=0.4726, s\left(a_{3}\right)=0.3993 \\
s\left(a_{4}\right)=0.4853, s\left(a_{5}\right)=0.5908\end{array}$ & $x_{1} \succ x_{5} \succ x_{4} \succ x_{2} \succ x_{3}$ \\
\hline $\begin{array}{l}\text { Method based on the } q \text {-ROFWA operator pro- } \\
\text { posed by Liu and Wang [30] }\end{array}$ & $\begin{array}{c}s\left(a_{1}\right)=0.4785, s\left(a_{2}\right)=0.4936, s\left(a_{3}\right)=0.3559 \\
s\left(a_{4}\right)=0.3874, s\left(a_{5}\right)=0.5044\end{array}$ & $x_{5} \succ x_{2} \succ x_{1} \succ x_{4} \succ x_{3}$ \\
\hline $\begin{array}{l}\text { Method based on the } q-\text { ROFWMM operator } \\
\text { proposed in this paper }\end{array}$ & $\begin{array}{c}s\left(a_{1}\right)=0.6850, s\left(a_{2}\right)=0.5961, s\left(a_{3}\right)=0.5833 \\
s\left(a_{4}\right)=0.5938, s\left(a_{5}\right)=0.6754\end{array}$ & $x_{1} \succ x_{5} \succ x_{2} \succ x_{4} \succ x_{3}$ \\
\hline $\begin{array}{l}\text { Method based on the } q-\text { ROFWDMM operator } \\
\text { proposed in this paper }\end{array}$ & $\begin{array}{c}s\left(a_{1}\right)=-0.3477, s\left(a_{2}\right)=-0.4570, s\left(a_{3}\right)=-0.5303 \\
s\left(a_{4}\right)=-0.4754, s\left(a_{5}\right)=-0.3739\end{array}$ & $x_{1} \succ x_{5} \succ x_{2} \succ x_{4} \succ x_{3}$ \\
\hline 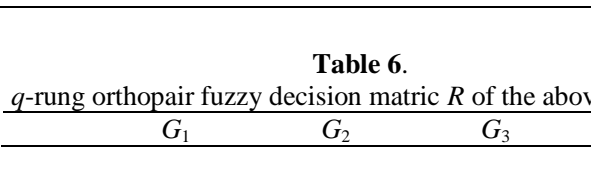 & 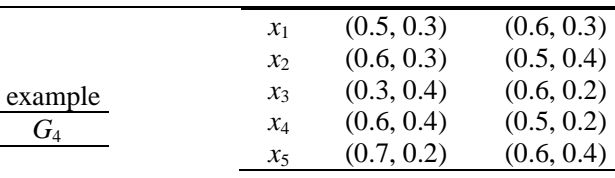 & $\begin{array}{ll}(0.6,0.3) & (0.7,0.3) \\
(0.4,0.5) & (0.5,0.2) \\
(0.3,0.6) & (0.6,0.4) \\
(0.4,0.4) & (0.5,0.5) \\
(0.6,0.3) & (0.4,0.3) \\
\end{array}$ \\
\hline
\end{tabular}
the methods base on IFWMM and IFWDMM opera intuitionistic fuzzy Bonferroni mean (WIFBM) de-

Table 7. Ranking results by different methods of the Example 
tors proposed by Liu and $\mathrm{Li}$ [36], and the method based on the $q$-ROFWA operator proposed by Liu and Wang [30] to solve the same problem and conduct some comparative analysis. The results are shown in Table 7.

From Table 7 we can find out the ranking results by the method in $[4,5,30,35,38,39]$ are different from the ranking results by the methods in [36] and the present paper. The reasons can be explained as follows. Methods in [4, 30, 38] assume that all the attributes are independent, which means that interrelationship among arguments are not taken into consideration in the fusion process. Methods in $[5,35$, 39] consider the interrelationship among attribute values. However, they can only capture the interrelationship between any two attribute values but cannot reflect the interrelationship among all input arguments. The ranking results are the same using the methods in [36] and the methods in this paper. All these methods consider the interrelationship among all input arguments. Therefore, the ranking results are the same though the methods in [36] are based on the IFNs and methods in this paper are based on the $q$-ROFNs. In addition, if we set $q=2$, then the $q$-ROFWMM and the $q$-ROFWDMM operators will reduce to the Pythagorean fuzzy weighted Muirhead mean (PFWMM) operator and the Pythagorean fuzzy weighted dual Muirhead mean (PFWDMM) operator respectively. If we utilize the PFWMM operator to aggregate decision makers' assessments, we can get the scores of the overall assessments:

$$
\begin{gathered}
s\left(a_{1}\right)=0.7571 \quad s\left(a_{2}\right)=0.6844 \quad s\left(a_{3}\right)=0.6610 \\
s\left(a_{4}\right)=0.6798 \quad s\left(a_{5}\right)=0.7488
\end{gathered}
$$

Thus, the ranking result is also $x_{1} \succ x_{5} \succ x_{2} \succ x_{4} \succ x_{3}$. If we utilize the PFWDMM to aggregate decision makers' preference, the following scores can be obtained:

$$
\begin{gathered}
s\left(a_{1}\right)=-0.4439 \quad s\left(a_{2}\right)=-0.5424 \quad s\left(a_{3}\right)=-0.6106 \\
s\left(a_{4}\right)=-0.5604 s\left(a_{5}\right)=-0.4656
\end{gathered}
$$

Thus, the ranking result is also $x_{1} \succ x_{5} \succ x_{2} \succ x_{4} \succ x_{3}$. The reason why the ranking results by utilizing the approaches based on the IFWMM, IFDWMM, PFWMM, PFWDMM, $q$-ROFWMM and $q$-ROFWDMM operators are the same is that all of them can capture the interrelationship among all input arguments. However, the proposed methods in this paper are more powerful as they are based on $q-$ ROFNs and the others are based on the IFNs and Pythagorean fuzzy numbers (PFNs). For instance, if the attribute value of $G_{1}$ of alternative $x_{1}$ is $(0.8,0.7)$, then it cannot be represented by the IFNs of the PFNs. In this circumstance, the methods based on the IFWMM, IFDWMM, PFWMM, PFWDMM operators do not work. However, the methods based on the $q$-ROFWMM and $q$-ROFWDMM operators can still work as $(0.8,0.7)$ can be represented by $q-$ ROFNs.

Evidently, as our methods are based on $q$-ROFNs and can consider the interrelationship among all aggregated inputs, they are more useful, powerful and reasonable than existing methods.

\section{Conclusions}

The recently proposed $q$-ROFS is a powerful technology to describe and express decision makers' assessments over alternatives in MAGDM. In this paper, we extend the MM to $q$-ROFSs and develop $q$ ROFMM, $q$-ROFWMM, $q$-ROFDMM and qROFWDMM operators. In addition, we present some special cases of the proposed operators with the parameter vector. Moreover, we discuss some desirable properties of these operators. Further, we establish a novel method to MAGDM problems where attribute values take the form of $q$-ROFNs based on the proposed operators. We also provide a numerical example as well as some comparative analysis. The results demonstrate that the proposed method is a generalized and flexible method compared with other existing methods. In the future works, we will apply the proposed method to practical MAGDM problems.

\section{Acknowledgement}

This work was partially supported by National Natural Science Foundation of China (Grant number 71532002, 61702023), Beijing Social Science Foundation (Grant number 15JDJGC019), and the Fundamental Fund for Humanities and Social Sciences of Beijing Jiaotong University (Grant number 2016JBZD01).

\section{References}

[1] L.A. Zadeh, Fuzzy sets, Information and Control 8 (1965), 338-353. 
[2] F. Blanco-Mesa, J.M. Merigó, and A.M. Gil-Lafuente, Fuzzy decision making: A bibliometric-based review, Journal of Intelligent \& Fuzzy Systems 32 (2017), 2033-2050.

[3] W.S Liu and H.C. Liao, A bibliometric analysis of fuzzy decision research during 1970-2015, International Journal of Fuzzy Systems, 19 (2017), 1-14.

[4] J.M. Merigó, Fuzzy decision making using immediate probabilities, Computers \& Industrial Engineering 58 (2010), 651657

[5] J.M. Merigó, A.M. Gil-Lafuente, and R.R. Yager, An overview of fuzzy research with bibliometric indicators, Applied Soft Computing 27 (2015), 420-433.

[6] K.T. Atanassov, Intuitionistic fuzzy sets, Fuzzy Sets and Systems 33 (1989), 37-46.

[7] D.J. Yu and H.C. Liao, Visualization and quantitative research on intuitionistic fuzzy studies, Journal of Intelligent \& Fuzzy Systems 30 (2016), 3653-3663.

[8] D.J. Yu and S.S. Shi, Researching the development of Atanassov intuitionistic fuzzy set: Using a citation network analysis, Applied Soft Computing 32 (2015), 189-198.

[9] Z. Xu, Intuitionistic fuzzy aggregation operators, IEEE Transactions on fuzzy systems 15 (2007), 1179-1187.

[10]Z. Xu and R.R. Yager, Intuitionistic fuzzy Bonferroni means, IEEE Transactions on Systems, Man, and Cybernetics, Part B (Cybernetics) 41 (2011), 568-578.

[11] M. Xia, Z. Xu, and B. Zhu, Geometric Bonferroni means with their application in multi-criteria decision making, Knowledge-Based Systems 40 (2013), 88-100.

[12]R. Verma, Generalized Bonferroni mean operator for fuzzy number intuitionistic fuzzy sets and its application to multiattribute decision making, International Journal of Intelligent Systems, 30 (2015), 449-519.

[13]D.J. Yu, Intuitionistic fuzzy geometric Heronian mean aggregation operators, Applied Soft Computing, 13 (2013), 12351246.

[14]R. Verma and B.D. Sharma, Intuitionistic fuzzy Einstein prioritized weighted average operators and their application to multiple attribute group decision making, Applied Mathematics and Information Sciences 9 (2015), 3095-3107.

[15]R. Verma and B.D. Sharma, A new measure of inaccuracy with its application to multi-criteria decision making under intuitionistic fuzzy environment, Journal of Intelligent and Fuzzy Systems 27 (2014), 1811-1824.

[16]R. Verma and B.D. Sharma, Exponential entropy on intuitionistic fuzzy sets, Kybernetika, 49 (2013), 114-127

[17]X.F. Wang, J.Q. Wang, and W.E. Yang, Multi-criteria group decision making method based on intuitionistic linguistic aggregation operators, Journal of Intelligent \& Fuzzy Systems 26 (2014), 115-125.

[18] M.M. Xia, Point operators for intuitionistic multiplicative information, Journal of Intelligent \& Fuzzy Systems 28 (2015) 615-620.

[19]X. Zhou, R. Zhao, F. Yu, and H. Tian, Intuitionistic fuzzy entropy clustering algorithm for infrared image segmentation, Journal of Intelligent \& Fuzzy Systems 30 (2016), 1831-1840.

[20]Z. Wang, Z. Xu, S. Liu, and Z. Yao, Direct clustering analysis based on intuitionistic fuzzy implication, Applied Soft Computing 23 (2014), 1-8.

[21] L.H. Son and P.H. Phong, On the performance evaluation of intuitionistic vector similarity measures for medical diagnosis1, Journal of Intelligent \& Fuzzy Systems 31 (2016), 1597 1608.

[22] C.M. Own, Switching between type-2 fuzzy sets and intuitionistic fuzzy sets: an application in medical diagnosis, Applied Intelligence 31 (2009), 283.
[23] S.M. Chen, S.H. Cheng, and T.C. Lan, A novel similarity measure between intuitionistic fuzzy sets based on the centroid points of transformed fuzzy numbers with applications to pattern recognition, Information Sciences 343 (2016), 15-40.

[24] C.M. Hwang, M.S. Yang, W.L. Hung, and M.G. Lee, A similarity measure of intuitionistic fuzzy sets based on the Sugeno integral with its application to pattern recognition, Information Sciences 189 (2012), 93-109.

[25] R.R. Yager, Pythagorean membership grades in multi-criteria decision making, IEEE Transactions on Fuzzy Systems 22 (2014), 958-965.

[26]X.D. Peng and J.D. Dai, Approaches to Pythagorean fuzzy stochastic multi-criteria decision making based on prospect theory and regret theory with new distance measure and score function, International Journal of Intelligent Systems 25 (2017), 1187-1214.

[27]G. Wei, Pythagorean fuzzy interaction aggregation operators and their application to multiple attribute decision making, Journal of Intelligent \& Fuzzy Systems 33 (2017), 2119-2132.

[28] S.A.K. Muhammad, S. Abdullah, M. Yousaf Ali, I. Hussain, and M. Farooq, Extension of TOPSIS method base on Choquet integral under interval-valued Pythagorean fuzzy environment, Journal of Intelligent \& Fuzzy Systems 34 (2018), 267-282.

[29] G. Wei, M. Lu, F.E. Alsaadi, T. Hayat, and A. Alsaedi, Pythagorean 2-tuple linguistic aggregation operators in multiple attribute decision making, Journal of Intelligent \& Fuzzy Systems 33 (2017), 1129-1142.

[30] Y. Geng P. Liu, F, Teng, and Z. Liu, Pythagorean fuzzy uncertain linguistic TODIM method and their application to multiple criteria group decision making, Journal of Intelligent \& Fuzzy Systems 33 (2017), 3383-3395.

[31]Z.M. Liu, P.D. Liu, W.L. Liu, and J.Y. Pang, Pythagorean uncertain linguistic partitioned Bonferroni mean operators and their application in multi-attribute decision making, Journal of Intelligent \& Fuzzy Systems 32 (2017), 2779-2790.

[32] Y. Qin, Y. Liu, and Z. Hong, Multicriteria decision making method based on generalized Pythagorean fuzzy ordered weighted distance measures, Journal of Intelligent \& Fuzzy Systems 33 (2017), 3665-3675.

[33] Y. Xu, X.P. Shang, and J. Wang, Pythagorean fuzzy interaction Muirhead means with their applications to multi-attribute group decision making, Information 9 (2017), 157.

[34] Y.P. Xing, R.T. Zhang, J. Wang, and X.M. Zhu, Some new Pythagorean fuzzy Choquet-Frank aggregation operators for multi-attribute decision making, International Journal of Intelligent Systems, online.

[35]L. Li, R.T. Zhang, J. Wang, X. M. Zhu, and Y.P. Xing, Pythagorean fuzzy power Muirhgead mean operators with their application to multi-attribute decision making, Journal of Intelligent \& Fuzzy Systems, in press.

[36] R.T. Zhang, J. Wang, X.M. Zhu, M.M. Xia, and M. Yu, Some generalized pythagorean fuzzy bonferroni mean aggregation operators with their application to multiattribute group decision-making, Complexity 2017 (2017), 1-16.

[37] R.R. Yager, Generalized orthopair fuzzy Sets, IEEE Transactions on Fuzzy Systems 25 (2017), 1222-1230.

[38]P.D. Liu and P. Wang, Some $q$-rung orthopair fuzzy aggregation operators and their applications to multiple-attribute decision making, International Journal of Intelligent Systems 33 (2018), 259-280.

[39]C. Bonferroni, Sulle medie multiple di potenze, Bollettino dell'Unione Matematica Italiana 5 (1950), 267-270

[40]S. Sykora, Mathematical means and averages: Generalized Heronian means, Stan's Library, Ed.S.Sykora 3 (2009). 
[41]C. Maclaurin, A second letter to Martin Folkes, Esq.; concerning the roots of equations, with the demonstration of other rules in algebra, Phil, Transaction 36 (1729), 59-96.

[42]R.F. Muirhead, Some methods applicable to identities and inequalities of symmetric algebraic functions of $\mathrm{n}$ letters, Proceedings of the Edinburgh Mathematical Society 21 (1902) 144-162.

[43]P.D. Liu and J.L. Liu, Some q-rung orthopair fuzzy Bonferroni mean operators and their application to multi-attribute group decision making, International Journal of Intelligent System 33 (2018), 315-347.

[44]P.D. Liu and P. Wang, Multiple-attribute decision making based on Archimedean Bonferroni operators of q-rung orthopair fuzzy numbers, IEEE Transactions on Fuzzy Systems, online.

[45] G.W. Wei, H. Gao, and Y. Wei, Some q-rung orthopair fuzzy Heronian mean operators in multiple attribute decision making,
International Journal of Intelligent Systems 33 (2018), 1426 1458

[46]P.D. Liu and D.F. Li, Some Muirhead mean operators for intuitionistic fuzzy numbers and their applications to group decision making, Plos one 12 (2017), 423-431.

[47]G.W. Wei, Some induced geometric aggregation operator with intuitionistic fuzzy information and their application to group decision making, Applied Soft Computing 10 (2010), 423-431.

[48]H. Garg, A new generalized Pythagorean fuzzy information aggregation using Einstein operations and its application to decision making, International Journal of Intelligent Systems 31 (2016), 886-920.

[49]D.C. Liang, Z.S. Xu, and A.P. Darko, Projection model for fusing the information of Pythagorean fuzzy multi-criteria group decision making based on geometric Bonferroni mean, International Journal of Intelligent Systems 32 (2017), 966987. 